\title{
Study on Effect of Process Parameters on End Wear of Tool Electrode during Planetary EDM of Ti-6Al-4V
}

\author{
Vishal J. Mathai, Harshit K. Dave, and Keyur P. Desai
}

\begin{abstract}
Electro Discharge Machining (EDM) is one of the most widely accepted advanced machining process to machine hard to machine electrically conductive materials. However, the inferior physical properties of the workpiece tend to make process unstable resulting into heavy loss of material from the tool electrode thereby leading in to generation of inaccurate features. In present work, an attempt has been made to study the effect of various process parameters viz. pulse ON time, duty factor, gap voltage and polarity of the tool electrode on end wear of the tool electrode and wear ratio during planetary EDM of Ti-6Al-4V. One factor at a time methodology has been employed to study the parameter effects. Results suggest that distortion on the tool electrode during EDM of Ti-6Al-4V is highly influenced by the pulse ON time level as well as polarity of the tool electrode employed. Further, it has also been understood that lower levels of duty factor and higher levels of gap voltage are preferable for efficient machining of titanium alloys.
\end{abstract}

Index Terms-EDM, planetary, titanium, tool kinematics, wear.

\section{INTRODUCTION}

Titanium and its alloys have wide range of application in various sectors like aerospace, biomedical, chemical processing plants etc. owing to its high strength to weight ratio, excellent biocompatibility and good corrosion resistance. But the inferior property values for thermal conductivity, elastic modulus, volume specific heat etc. make it a material difficult to machine [1], [2]. Therefore advanced machining techniques like Electro Discharge Machining $(\mathrm{EDM})$ process is commonly used for processing such materials. The process removes material with the aid of repetitive and controlled electrical sparks in the presence of a dielectric medium, which results into localized rise in temperature on both tool electrode and workpiece surface, leading to melting and vaporization of the same [3]. The debris formed is immediately flushed out from the machining zone by the dielectric fluid.

Even though the process can be applied for machining titanium based alloys, one of the issues that have been reported is the relatively higher intensity of wear of the tool electrode during machining. As EDM is a process in which the negative image of the tool electrode is generated on the

Manuscript received March 10, 2016; revised June 21, 2016.

The authors are with the Department of Mechanical Engineering, S. V. National Institute of Technology, Surat, Gujarat - 395007, India (e-mail: vishaljohnmathai@gmail.com,

keyur_desai@yahoo.com). workpiece, a worn out tool will result into inaccurate final feature. Further, this aberration may be aggravated by factors like improper selection of parameter conditions and tool material, ineffective flushing etc. Therefore, it is necessary to incorporate process improvement techniques during EDM of these types of materials so that the process efficiency can be improved.

Many process improvements techniques like usage of different tool geometries like bundled [4], channeled [5] etc., application of tool kinematics like rotation [6], vibration [7], orbiting [8] etc. have been reported for efficient machining of titanium and it alloys. Concept of cryogenic cooling of the tool electrode has also been studied by researchers and reported to have positive effect on process characteristics [9]. Out of these process improvement techniques, orbiting of the tool electrode have multi-facetted advantages as it improves flushing at the inter electrode gap, reduces tool wear and improves surface finish of the final feature. Further, the tooling cost can also be reduced significantly as a bigger cavity can be made using a smaller electrode [10].

Different modes of planetary tool actuation strategies have been studied by researchers in EDM process carried out at micro as well as macro level. El-Taweel and Hewidy [11] studied the effectiveness of tool actuation strategies viz., spiral and helix for the generation of circular cavities. Similarly, Bamberg and Heamawatanachi [12] assessed strategies like z-slicing, cylindrical slicing and z-spiraling for machining circular micro holes. The application of such tool actuation techniques has also been reported by Guo et al. for creating high aspect ratio micro features [13]. Further, simultaneous application of tool orbiting as well as tool rotation has also been reported by Egashira et al. and Ziada and Koshy for process improvement [14], [15].

It has been observed from these literatures that orbital or planetary actuation of the tool electrode facilitates in attainment of uniform as well as relatively lower distortion on the tool with good wear ratio as well dimensional accuracy as compared to conventional die sinking EDM technique [16]-[18]. It has also been observed that majority of the studies related to orbital or planetary tool actuation in EDM have dealt with generation of circular features. When such strategies applied for non-circular feature generation, different wear characteristics may be anticipated. Further, it has also been noted that no detailed studies regarding the application of planetary tool actuation during EDM of titanium and its alloys is reported. Therefore, the objective of this work is to understand the effect of process parameters on end wear on the tool electrode and wear ratio during the generation of square shaped cavities on a titanium alloy using planetary EDM. 


\section{EXPERIMENTAL DETAILS}

The experiments have been carried out on Joemars AZ50R EDM with attachment for orbital tool actuation (Fig. 1). Commercially available hydrocarbon based dielectric oil has been used as the medium. Side injection flushing with 0.25 $\mathrm{kg} / \mathrm{cm}^{2}$ pressure has been used for flushing during the process.

For tool actuation, helical tool path strategy has been employed as the same is reported to have good effectiveness for generation of square shaped features than other planetary strategies like diagonal [19]-[20]. In helical tool path strategy, the tool is actuated along a path parallel to the final outline of the cavity, at a distance equal to tool path offset from the axis of the final cavity (Fig. 2). During this motion, simultaneous feed in $\mathrm{Z}$ direction is also be given, making the final tool path look like a square shaped helix.
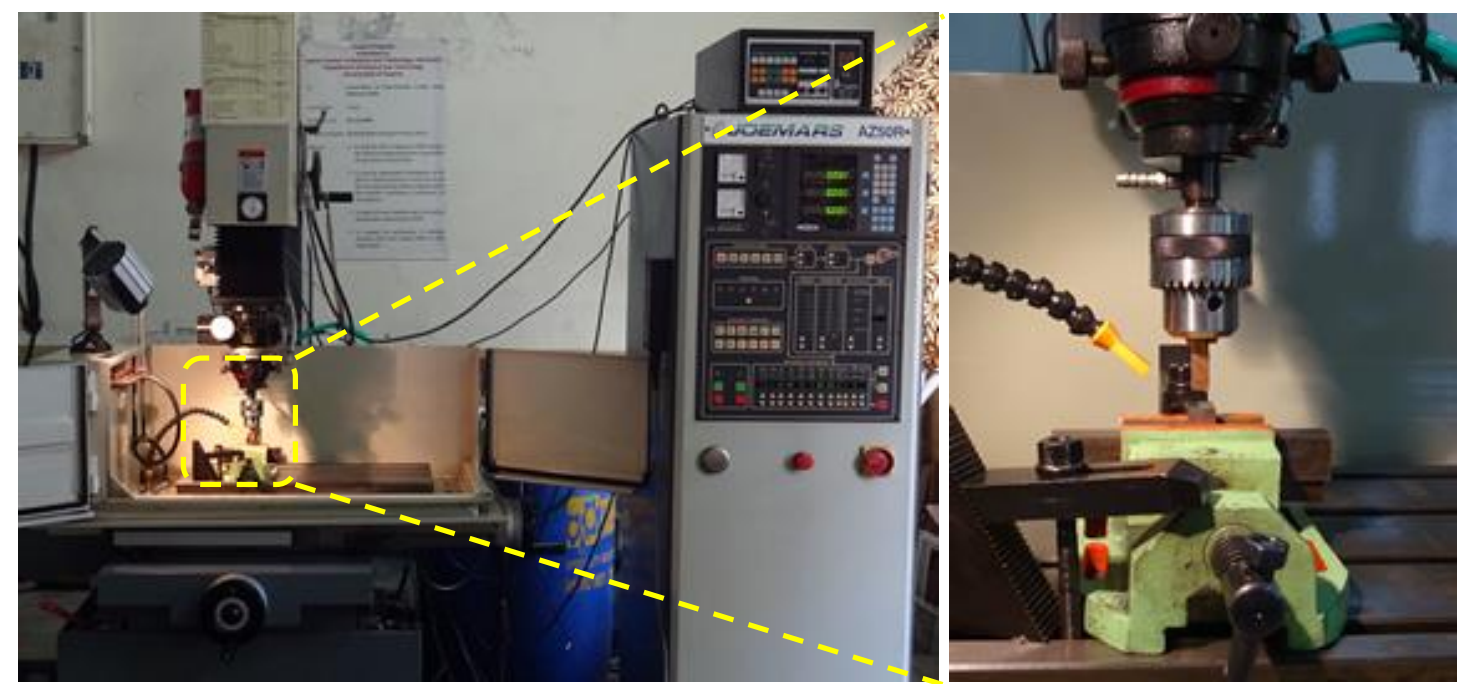

Fig. 1. Experimental set up.

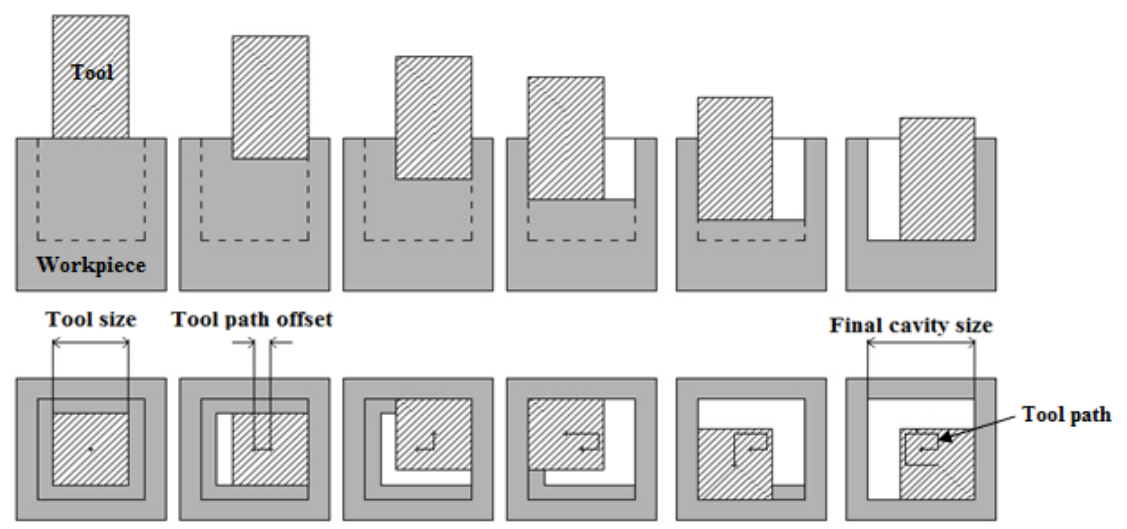

Fig. 2. Tool motion strategy used for square cavity generation.

The experiments have been designed using one factor at a time methodology in which effect of one factor is studied by keeping other factors constant. In present work, four process parameters have been considered viz. pulse ON time, duty factor, gap voltage and polarity of the tool electrode. Current, even though a significant parameter in EDM process has been kept at a constant level of $13 \mathrm{~A}$ as the authors during their initial investigations observed best performance in terms of material removal rate and machining time at that particular level. Similar observation has been reported by Hascalik and Caydas in their research work also [21]. Table I shows the parameter combinations that have been employed for experimentations.

Wear on the tool electrode can be evaluated in different ways and in present work, end wear has been considered as the response. End wear is measured as the loss in tool electrode material in terms of length. The response has been calculated by measuring the difference in length of the tool electrode before and after machining which is schematically shown in Fig. 3. Expression used for calculation of the same is given below:

$$
\text { Wear Ratio, } W R=\left(W_{w b}-W_{w a}\right) \rho_{t} /\left(W_{t b}-W_{t a}\right) \rho_{w}
$$

where $W_{w b / a}=$ weight of the workpiece before/after machining (gm), $W_{t b / a}=$ weight of the tool electrode before/after machining $(\mathrm{gm}), \rho_{w / t}=$ density of the workpiece/tool electrode material $\left(\mathrm{gm} / \mathrm{mm}^{3}\right)$.

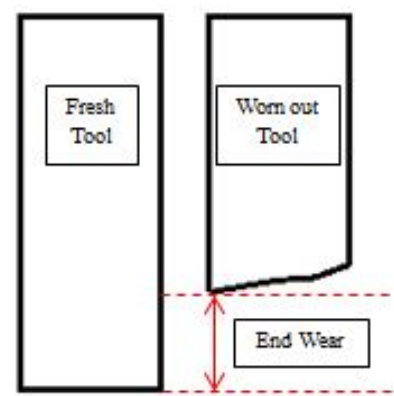

Fig. 3. End wear measurement. 
TABLE I: PARAMETERS AND THEIR LEVELS CONSIDERED FOR EXPERIMENTATION

\begin{tabular}{|c|c|c|c|c|}
\hline \multirow[b]{2}{*}{ Constant parameters } & \multicolumn{4}{|c|}{ Variable parameters } \\
\hline & $t_{O N}$ & $D F$ & Pol. & $\boldsymbol{V}$ \\
\hline$t_{O N}$ & $40,100,165,240$ & 0.3 & - & 70 \\
\hline$D F$ & 240 & $0.2,0.3,0.4$ & - & 70 \\
\hline Pol. & 40,240 & 0.3 &,-+ & 70 \\
\hline $\boldsymbol{V}$ & 240 & 0.3 & - & $40,70,100$ \\
\hline$t_{O N}=$ Pulse ON time $(\mu s)$ & $D F=$ Duty factor & Pol. $=$ Polarity of tool electrode & & $V=$ Gap voltage $(V)$ \\
\hline \multicolumn{2}{|c|}{$\begin{array}{l}\text { Current }=13 \mathrm{~A} \\
\text { Flushing pressure }=0.25 \mathrm{~kg} / \mathrm{cm}^{2}\end{array}$} & $\begin{array}{l}\text { Tool path offset }=0.5 \mathrm{~mm} \\
\text { Scanning speed }=0.13 \mathrm{~mm} / \mathrm{s}\end{array}$ & \multicolumn{2}{|c|}{$\begin{array}{l}\text { Workpiece - Ti-6Al-4V } \\
\text { Toolelectrode-Copper }\end{array}$} \\
\hline
\end{tabular}

For experimentation, titanium grade 5 alloy (Ti-6Al-4V) which is widely used for making high strength prosthetics, chemical processing equipment etc. has been selected as the work piece material. Electrolytic copper has been used as the tool electrode owing to its good thermal and electrical conductivity. As the final cavity shape is square and the final cavity size has been decided as $10 \mathrm{~mm} \times 10 \mathrm{~mm} \times 10 \mathrm{~mm}$, tool electrodes with cross sectional size of $9 \mathrm{~mm} \times 9 \mathrm{~mm}$ with a tool path offset of $0.5 \mathrm{~mm}$ have been used for machining.

Prior to taking measurements, the electrodes have been rinsed and cleaned thoroughly using acetone. The length measurements have been taken using vision measurement system having a least count of $1 \mu \mathrm{m}$. For the calculation of wear ratio, difference in weight of workpiece and tool electrode before and after machining has been measured using a digital weighing machine having a least count of $0.1 \mathrm{mg}$. The obtained data is then divided by corresponding material density to obtain the volumetric wear. Figs. 4-7 show the effect of process parameters on end wear and wear ratio during planetary EDM of Ti-6Al-4V.

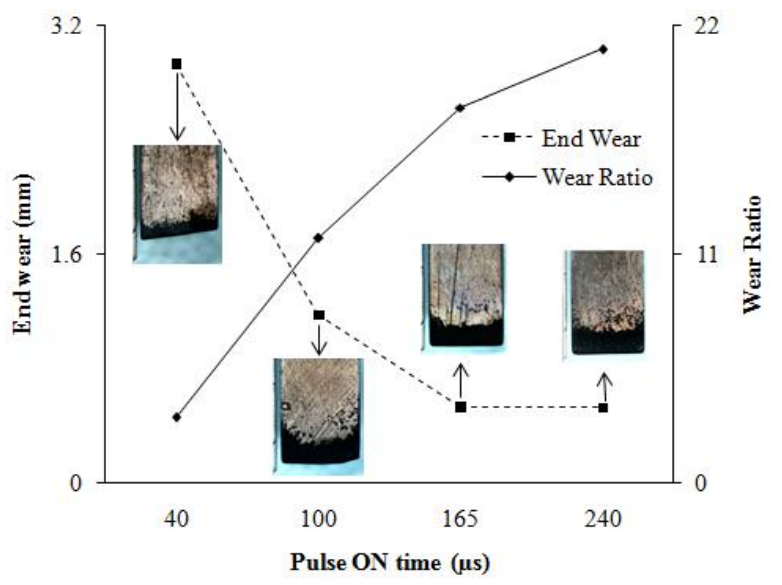

Fig. 4. Effect of Pulse ON time on end wear and wear ratio.

\section{RESULTS AND DISCUSSIONS}

\section{A. Effect of Pulse ON Time}

Fig. 4 shows the effect of Pulse ON time on End wear as well as wear ratio. It can be clearly seen that the response decreases with increase in pulse $\mathrm{ON}$ time and at lower pulse ON time, the wear is observed to be very intense. It is also worth noting that the end wear is almost constant at higher pulse $\mathrm{ON}$ times.

At higher pulse ON time, the heat build up in the tool electrode will result in to the generation of a carbon layer formed by the dissociation of hydrocarbon based dielectric fluid and the same will act as a protective layer from tool erosion. Further, the energy density of the discharge spot will be lower due to the expansion of the plasma channel at such conditions, leading to lower erosion from the tool electrode surface.

Looking in to the wear characteristics of the tool electrode used under different pulse ON time conditions, it can be seen the tip of the electrodes used under lower pulse ON time conditions are slightly tapered. This may be due to the difference in amount of debris getting accumulated in the inter electrode gap due to the application of side flushing. As side injection flushing has been provided from the left side of the tool electrode in present study, the presence of debris may be relatively lower at the left side area. However, the flow of debris may get blocked by the right side wall of the cavity being generated, resulting into debris accumulation at those points. This may result into undesirable sparking leading to unanticipated removal of material from the tool [22].

Further, it can be understood from the graph that the wear ratio can be obtained at higher pulse ON times. This may be due to the fact that at higher pulse ON times, the loss of material from the electrode is very low. This will result in removing the material from the workpiece more efficiently, resulting into attainment of higher wear ratio values at such conditions.

\section{B. Effect of Duty Factor}

The effects of duty factor on end wear and wear ratio are graphically shown in Fig. 5. It is evident from the figure that lower duty factor is preferable to keep end wear at a lower level. As duty factor is the ratio of pulse ON time to the total time for one machining cycle, an increase in duty factor will result into decrease in pulse OFF time. Under such conditions, the time available to provide flushing at the machining zone will be very less. This may result into accumulation of debris in the inter electrode gap, thereby resulting into occurrence of secondary sparking or arcing. This may intensify the wear on the tool electrode. Further, at higher duty factor, as the spark duration is higher, the heat buildup on the tool electrode will be higher. Such conditions may also amplify the occurrence of arcing in the machining zone and hence an increase in wear on the tool. Even though a lower level of duty factor aids in reducing the end wear, such a machining condition will also increase the total machining time significantly.

It can also be noticed that the rate of increase of end wear 
when the duty has been varied at lower levels is low. As such conditions result in reduction in end wear as well as increase in machining time, the duty factor must be selected in such a way that a proper balance between them can be maintained. Further, it can also be seen that the wear ratio reduces with increase in duty factor. The result can be considered obvious as increase in duty factor results in increase of wear of the tool electrode as discussed above. But, it is also worth noting that the extent of effect of duty factor on wear ratio is not as dominant as seen in the case of end wear.

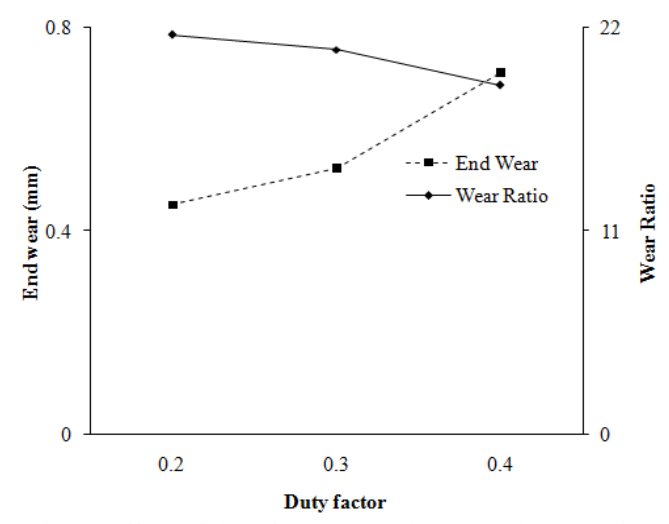

Fig. 5. Effect of duty factor on end wear and wear ratio.

\section{Effect of Gap Voltage}

Effect of gap voltage on end wear and wear ratio is shown in Fig. 6. It can be seen that the response decreases slightly with increase in gap voltage initially and then observed to increase with further increment. However, wear ratio is observed to decrease with increase in gap voltage. As gap voltage and spark gap are inter related, a lower gap voltage will result into smaller inter electrode gap. This may lead to ineffective removal of debris from the inter electrode gap and hence result into arcing. With increase in gap voltage, the inter electrode gap is correspondingly increase which will help in removal of debris effectively, thereby making the process more stable.

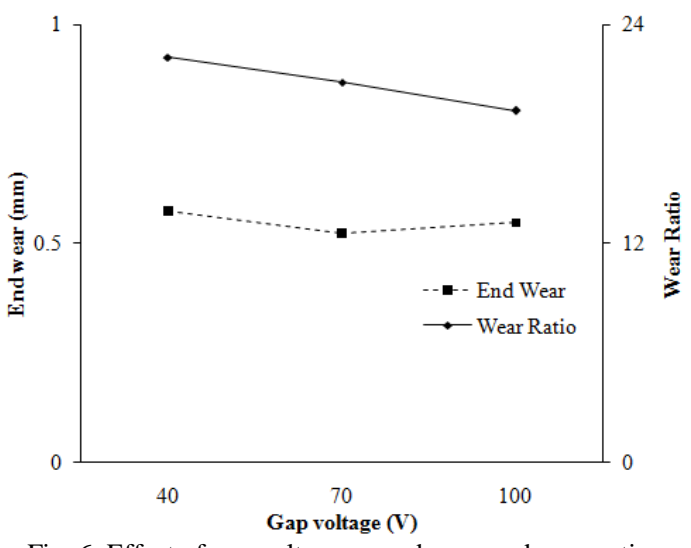

Fig. 6. Effect of gap voltage on end wear and wear ratio.

But when gap voltage is too high, the energy intensity of the sparks may reduce because of the large gap between the tool and the workpiece. This may result into reduction in material removal rate from the workpiece surface, leading to higher machining. Such conditions will result into prolonged exposure of the tool electrode to machining conditions, and hence higher wear on the tool electrode may be anticipated. It is also worth noting that the rate of variation in response with increase in gap voltage is very less. This shows that gap voltage have relatively lower significant effect on end wear of the tool electrode.

\section{Effect of Polarity of Tool Electrode}

Study on variation of polarity of the tool electrode has been carried out two levels of pulse ON time $-40 \mu \mathrm{s}$ and $240 \mu \mathrm{s}$. The effect of the same on end wear as well as wear ratio is graphically shown in Fig. 7.

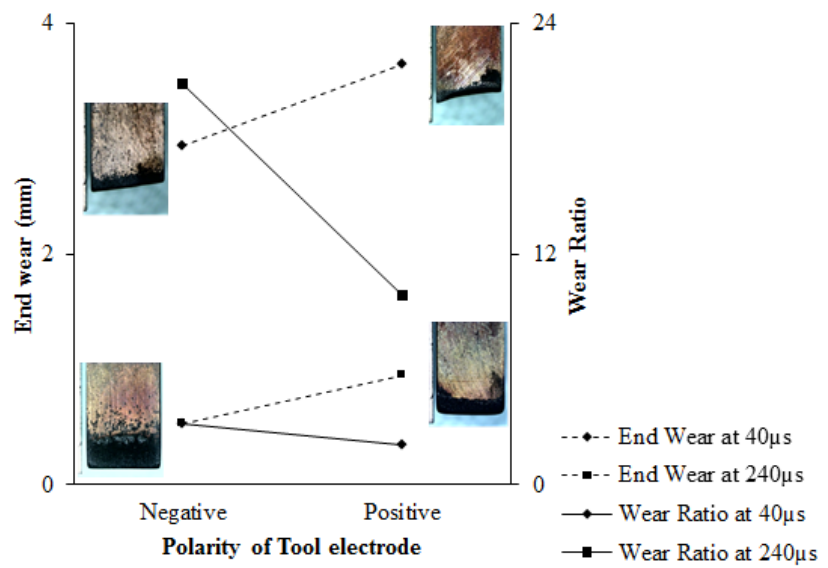

Fig. 7. Effect of polarity of the tool electrode on end wear and wear ratio.

It can be clearly seen that irrespective of the pulse ON time condition, negative polarity of the tool electrode resulted into lower end wear than that used under positive polarity. It is also evident from the images of the tool electrodes shown in Fig. 7 that the wear is very much intense on tool electrodes used under positive polarity. In EDM process, the heat generated in the anode is higher than that in cathode [23], [24].

The variation in wear intensity with change of polarity depends on the type of particle that impact on the tool electrode - positive ion or electron. As electrons have higher mass than ions, they possess higher kinetic energy and the impact of the same on a positive electrode may result into relatively higher heat buildup. This may result into easy erosion of material from the tool surface. Further, an increase in temperature will also result into conditions of arcing, thereby increasing the possibility of wearing out of the tool electrode [25].

It can also be observed from figure that the negative polarity favours in the attainment of higher wear ratio at both higher and lower pulse ON time conditions. This is because of the high end wear on the tool electrode at such conditions, which will result into removal of lesser volume of material from the workpiece resulting into lower wear ratio.

\section{CONCLUSIONS}

An attempt has been made to study the effect of various process parameters on End wear of the tool electrode and wear ratio during planetary EDM of Ti-6Al-4V alloy. Further, to study the effectiveness of the process, effect of parameters on wear ratio has also been investigated. Results suggest that the pulse ON time has a significant effect on both end wear of the tool electrode, wear characteristics and wear ratio and higher pulse $\mathrm{ON}$ time levels are preferable for efficient 
machining. It has also been understood that even though duty factor is observed to have an effect on end wear, the effect of same on wear ratio is low. Polarity of the tool electrode is also found to have an effect on both responses and results suggests the use of negative polarity for machining Ti-6Al-4V.

\section{ACKNOWLEDGMENT}

The authors thank Gujarat Council of Science and Technology (GUJCOST), Government of Gujarat, India for the financial support for this work through research grant vide grant permission GUJCOST/MRP/2014-15/402.

\section{REFERENCES}

[1] S. Pervaiz, A. Rashid, I. Deiab, and M. Nicolescu, "Influence of tool materials on machinability of tianium- and nickel- based alloys: A review," Materials and Manufacturing Processes, vol. 29, no. 3, pp. 219-252, March 2014.

[2] S. R. Chauhan and K. Dass, "Optimization of machining parameters in turning of titanium (Grade-5) alloy using response surface methodology," Materials and Manufacturing Processes, vol. 27, no. 5, pp. 531-537, Aug. 2011.

[3] K. H. Ho and S. T. Newman, "State of the art electrical discharge machining (EDM)," International Journal of Machine Tools and Manufacture, vol. 43, no. 13, pp. 1287-1300, October 2003.

[4] L. Gu, L. Li, W. Zhao, and K. P. Rajurkar, "Electrical discharge machining of TI6AL4V with a bundled electrode," International Journal of Machine Tools and Manufacture, vol. 53, no. 1, pp. 100-106, Feb. 2012.

[5] O. Yilmaz and M. A. Okka, "Effect of single and multi-channel electrodes application on EDM fast hole drilling performance," The International Journal of Advanced Manufacturing Technology, vol. 51, no. 1, pp. 185-194, Apr. 2010.

[6] R. Nastasi amd P. Koshy, "Analysis and performance of slotted tools in electrical discharge drilling," CIRP Annals - Manufacturing Technology, vol. 63, pp. 205-208, Apr. 2014.

[7] M. R. Shabgard, H. Alenabi, "Ultrasonic assisted electrical discharge machining of Ti-6AL-4V alloy," Materials and Manufacturing Processes, vol. 30, no. 8, pp. 991-1000, Feb. 2015.

[8] H. K. Dave, K. P. Desai, and H. K. Raval, "A Taguchi approach-based study on effect of process parameters in electro discharge machining using orbital tool movement," International Journal of Machining and Machinability of Materials, vol. 13, no. 1, pp. 52-66, 2013.

[9] V. Srivastava and P. M. Pandey, "Effect of process parameters on the performance of EDM process with ultrasonic assisted cryogenically cooled electrode," Journal of Manufacturing Processes, vol. 14, no. 3 , pp. 393-402, Aug. 2012.

[10] G. F. Benedict, Non Traditional Manufacturing Processes, Marcel Dekker Inc., New York, 1987.

[11] T. A. El-Taweel and M. S. Hewidy, "Enhancing the performance of electrical-discharge machining via various planetary modes," International Journal of Machining and Machinability of Materials, vol. 5, no. 2-3, pp. 308-320, 2009.

[12] E. Bamberg and S. Heamawatanachai, "Orbital electrode actuation to improve efficiency of drilling micro-holes by micro-EDM," Journal of Materials Processing Technology, vol. 209, no. 4, pp. 1826-1834, Feb. 2009.

[13] X. Guo, Z. Yu, Z. Lv, and J. Li, “Optimization of Planetary Movement Parameters for microdrilling by micro-electrical discharge machining," Journal of Micro and Nano Manufacturing, 2013.
[14] K. Egashira, T. Taniguchi, S. Hanajima, H. Tsuchiya, and M. Miyazaki, "Planetary EDM of micro holes," International Journal of Electrical Machining, vol. 11, pp. 15-18, March 2005.

[15] Y. Ziada and P. Koshy, "Rotating curvilinear tools for EDM of polygonal shapes with sharp corners," CIRP Annals- Manufacturing Technology, vol. 56, no. 1, pp. 221-224, June 2007.

[16] U. Teicher, S. Muller, J. Munzner, and A. Nestler, "Micro-EDM of carbon fibre reinforced plastics," Procedia CIRP, vol. 6, pp. 320-325, March 2013.

[17] Z. Y. Yu, K. P. Rajurkar, and J. Narasimham, "Effect of machining parameters on micro EDM and surface integrity," in. Proc the $18^{\text {th }}$ Annual Meeting of American Society for Precision Engineering, 2003.

[18] Z. Y. Yu, K. P. Rajurkar, and H. Shen, "High aspect ratio and complex shaped blind micro holes by micro EDM," CIRP Annals Manufacturing Technology, vol. 51, no. 1, pp. 359-362, July 2007.

[19] V. J. Mathai, H. K. Dave, and K. P. Desai, "Generation of square cavity by planetary EDM," Advanced Materials Research, vol. 1036, pp. 314-319, Oct. 2014.

[20] V. J. Mathai, H. K. Dave, and K. P. Desai, "Study on effect of tool motion strategies on tool wear characteristics during generation of non-ciruclar cavities by electro discharge machining process," International Journal of Machining and Machinability of Materials, vol. 17 , no. 2, pp. 150-164, 2015.

[21] A. Hascalik and U. Caydas, "Electrical discharge machining of titanium alloy (Ti-6Al-4V)," Applied Surface Science, vol. 253, no. 32, pp. 9007-9016, Sep. 2007.

[22] V. J. Mathai, H. K. Dave, and K. P. Desai, "Effect of flushing strategies responses during planetary EDM of Ti-6AL-4V," in. Proc Ninth International Conference on Precision Engineering, Meso, Micro and Nano Engineering, December 2015.

[23] Y. F. Luo and J. Tao, "Metal removal in EDM by shifting secondary discharge," Journal of Manufacturing Science and Engineering, vol. 131, no. 3, May 2009.

[24] H. Xia, H. Hashimoto, M. Kunieda, and N. Nishiwaki, "Measurement of energy distribution in continuous EDM process," Journal of the Japan Society for Precision Engineering, vol. 62, no. 8, pp. 1141-1145, 1996.

[25] P. Fonda, Z. Wang, K. Yamazaki, and Y. Akutsu, "A fundamental study on Ti-6Al-4V's thermal and electrical properties and their relation to EDM productivity," Journal of Materials Processing Technology, vol. 202, no. 1-3, pp. 583-589, June 2008.

Vishal John Mathai is a Ph.D. Research Scholar at the Department of Mechanical Engineering at S. V. National Institute of Technology, Surat, Gujarat, India. He has completed post-graduation in Mechanical engineering in 2012 from S. V. National Institute of Technology, Surat, Gujarat, India. At present he is working on planetary EDM of hard to machine materials. His research interests include advanced machining process, micro machining processes etc. Mr. Mathai is a member of American Society of Research.

Harshit K. Dave is serving as an Assistant Professor at the Department of Mechanical Engineering, S. V. National Institute of Technology, Surat, Gujarat, India. He has over ten years of teaching experience. His research interests include unconventional machining processes, micro machining processes, computer aided manufacturing and measurement, modelling and optimization of machining processes, etc.

Keyur P. Desai is serving as a Professor at the Department of Mechanical Engineering, S.V. National Institute of Technology, Surat, Gujarat, India. He has over twenty eight years of teaching and research experience. His research interests include unconventional machining processes, computer aided manufacturing, cryogenics and its application, etc. He has successfully handled several collaborative research projects funded by various government agencies. 